\title{
High prevalence of drug-resistance mutations in Plasmodium falciparum and Plasmodium vivax in southern Ethiopia Mirjam Schunk ${ }^{1}$, Wondimagegn P Kumma ${ }^{2}$, Isabel Barreto Miranda ${ }^{1}$, Maha E Osman ${ }^{3,4}$, Susanne Roewer ${ }^{4}$, Abraham Alano ${ }^{2}$, Thomas Löscher ${ }^{1}$, Ulrich Bienzle ${ }^{4}$ and Frank P Mockenhaupt*4
}

\author{
Address: ${ }^{1}$ Department of Infectious Diseases and Tropical Medicine, University of Munich, Leopoldstraße 5, 80802 Munich, Germany, ${ }^{2}$ Dilla \\ College of Teachers Education and Health Sciences, Debub University, PO Box 419, Awassa, Ethiopia, ${ }^{3}$ Malaria Research Centre (MalRC), \\ Department of Biochemistry, Faculty of Medicine, University of Khartoum, P.O. Box 102, Khartoum, Sudan and ${ }^{4}$ Institute of Tropical Medicine \\ and International Health, Charité - University Medicine Berlin, Spandauer Damm 130, 14050 Berlin, Germany \\ Email: Mirjam Schunk - schunk@lrz.uni-muenchen.de; Wondimagegn P Kumma - wondimagegnk@yahoo.com; \\ Isabel Barreto Miranda - barretomiranda@Irz.uni-muenchen.de; Maha E Osman - mamaelhadi@hotmail.com; \\ Susanne Roewer - susanne.roewer@charite.de; Abraham Alano - alanoabraham@yahoo.com; Thomas Löscher - loescher@lrz.uni-muenchen.de; \\ Ulrich Bienzle - ulrich.bienzle@charite.de; Frank P Mockenhaupt* - frank.mockenhaupt@charite.de \\ * Corresponding author
}

Published: 03 July 2006

Malaria Journal 2006, 5:54 doi:10.1 186/1475-2875-5-54

This article is available from: http://www.malariajournal.com/content/5/I/54

(C) 2006 Schunk et al; licensee BioMed Central Ltd.

This is an Open Access article distributed under the terms of the Creative Commons Attribution License (http://creativecommons.org/licenses/by/2.0), which permits unrestricted use, distribution, and reproduction in any medium, provided the original work is properly cited.
Received: 3I March 2006

Accepted: 03 July 2006

\begin{abstract}
Background: In Ethiopia, malaria is caused by both Plasmodium falciparum and Plasmodium vivax. Drug resistance of $P$. falciparum to sulfadoxine-pyrimethamine (SP) and chloroquine (CQ) is frequent and intense in some areas.

Methods: In 100 patients with uncomplicated malaria from Dilla, southern Ethiopia, P. falciparum $d h f r$ and dhps mutations as well as $P$. vivax $d h f r$ polymorphisms associated with resistance to SP and $P$. falciparum pfcrt and pfmdrl mutations conferring $C Q$ resistance were assessed.
\end{abstract}

Results: $P$. falciparum and $P$. vivax were observed in $69 \%$ and $31 \%$ of the patients, respectively. Pfdhfr triple mutations and pfdhfr/pfdhps quintuple mutations occurred in $87 \%$ and $86 \%$ of $P$. falciparum isolates, respectively. Pfcrt T76 was seen in all and pfmdrl Y86 in $81 \%$ of $P$. falciparum. The P. vivax dhfr core mutations NII7 and R58 were present in $94 \%$ and $74 \%$, respectively.

Conclusion: These data point to an extraordinarily high frequency of drug-resistance mutations in both $P$. falciparum and $P$. vivax in southern Ethiopia, and strongly support that both $\mathrm{SP}$ and $\mathrm{CQ}$ are inadequate drugs for this region.

\section{Background}

In Ethiopia, malaria is endemic in three quarters of the national territory [1] with Plasmodium falciparum predominating over Plasmodium vivax. Some $13-28 \%$ of deaths in children under five years of age are attributed to falciparum malaria [2]. Recently, a considerable increase in malaria morbidity has been noted in the south and southwest of Ethiopia. Possible reasons include climatic changes, drug resistance and migration (e.g. from Sudan). Also, epidemic outbreaks are now observed in highland areas [3]. 
In 1998 , intense resistance of $P$. falciparum to chloroquine (CQ) necessitated a change to sulfadoxine-pyrimethamine (SP) as first-line antimalarial drug in Ethiopia. However, recent data show a high mean SP treatment failure rate of $72 \%$ in some areas [4]. Consequently, another change to artemether-lumefantrine $(\mathrm{AL})$ was suggested in 2004 [5]. Yet, availability of AL is limited and 85\% of the population are living in rural areas with restricted access to health care giving rise to a high rate of presumptive treatment with available drugs like CQ or SP [6].

CQ resistance is associated with a T76 mutation of the $P$. falciparum chloroquine resistance transporter gene ( $p f c r t)$ [7] while a multidrug resistance analogue ( $p f m d r 1)$ Y86 variation may modulate its degree [8]. P. falciparum resistance to SP is conferred by mutations of the dihydropteroate synthase ( $p f d h p s)$ and dihydrofolate reductase ( $p f d h f r)$ genes [9]. In East Africa, the $p f d h f r / p f d h p s$ quintuple mutation (triple pfdhfr (N108-I51-R59) + pfdhps G437 + E540) is predictive for SP treatment failure, whereas in West Africa the $p f d h p s$ alleles currently do not seem to substantially improve the predictive value of the $p f d h f r$ triple mutation $[10,11]$.

$P$. vivax has long been considered intrinsically resistant to pyrimethamine [12]. Nevertheless, pvdhfr mutations N117 and R58 corresponding to P. falciparum dhfr mutations 108 and 59, respectively, are linked with SP resistance and seem to arise first under drug pressure $[13,14]$. A T117 mutation is seen in highly mutated genes [14]. Both double (N117-R58) and triple pvdhfr mutations (N117R58-L57) are associated with delayed parasite clearance following SP treatment [13].

Here, frequencies of relevant mutations in pfcrt, pfmdr1, $p f d h f r, p f d h p s$, and $p v d h f r$ among isolates from southern Ethiopia are presented.

\section{Methods}

The study was conducted in Dilla (population, approximately 15,000 ) located in a region characterized by the gentle slopes of the southern Ethiopian rift valley system ranging between an altitude of 1,400 to 2,000 metres above sea level. The mean annual temperature ranges between $17^{\circ} \mathrm{C}$ and $22.4^{\circ} \mathrm{C}$, and the mean annual rainfall is between 1200 and $1800 \mathrm{~mm}$ occurring in two rainy seasons from March to May and from July to December [15]. Both $P$. falciparum and $P$. vivax are endemic with pronounced seasonal peaks. Subjects were enrolled from January to March 2004, i.e. during high transmission at the end of a delayed rainy season. The study protocol was reviewed and approved by the Regional Government Health Bureau, Southern Nations, Ethiopia, and by the Ethical Committee, Charité-University Medicine, Berlin,
Germany, and informed consent was obtained from patients or parents.

One hundred patients presenting for primary health care with fever or a history of fever and microscopically confirmed uncomplicated malaria were recruited. Treatment followed national guidelines [16]. Finger-prick blood samples were collected and malaria parasites were counted on Giemsa-stained thick blood films per 200 white blood cells (WBC). Parasite density was calculated based on a putative mean of $8000 \mathrm{WBC} / \mu \mathrm{L}$. Aliquots of 10 $\mu \mathrm{L}$ of capillary blood were spotted on Whatman $3 \mathrm{MM}$ filter paper, and DNA was extracted by commercial kits (QIAmp blood kit, Qiagen). Parasite species was confirmed by nested polymerase chain reaction (PCR) assays [17]. Restriction fragment length polymorphisms of PCRgenerated amplicons were applied to characterize the codons: P. falciparum dhfr 51, 59, 108, pfdhps 436, 437, 540, 581, 613, pfcrt 76, pfmdr1 86, and P. vivax dhfr 57, 58, 61,117 . Restriction enzymes and conditions are described elsewhere $[18-20,13,14]$. Laboratory strains and DNAsamples of known genotype were used as positive controls. Mixed alleles (both wildtype and mutant alleles present) were considered mutant.

\section{Results}

The median age of the 100 patients ( 57 female, 43 male) was 17 years (range 8 months to 60 years). P. falciparum mono-infection, $P$. vivax mono-infection, and $P$. falciparum-P. vivax co-infection were seen in 66,28 , and 3 patients, respectively. In three samples, PCR yielded no result and at re-examination of thick films, no parasites were observed. The geometric mean parasite density of $P$. falciparum and $P$. vivax positive specimens was $21,797 / \mu \mathrm{L}$ (95\% confidence interval, $7,600-48,000)$ and $5,280 / \mu \mathrm{L}$ (95\% confidence interval, 880-16,800), respectively.

The results of $P$. falciparum genotyping for drug resistance mutations are summarized in Table 1. All isolates showed the CQ resistance $p f c r t \mathrm{~T} 76$ core mutation and four out of five additionally $p f m d r 1$ Y86. Likewise, all isolates exhibited the $p f d h f r$ core mutation N108 and no wildtype alleles at all three loci examined. In particular, the $p f d h f r$ triple mutation was seen in almost $90 \%$ (Table 1). Both pfdhps G437 and E540 occurred in 97\% whereas codons 436, 581 and 613 were all wildtype. Only two isolates displayed wildtype alleles in all pfdhps codons. Quadruple mutations were not detected but quintuple variants were found in $86 \%$ of $P$. falciparum-infected patients. As for $P$. vivax pvdhfr, a N117 mutation was present in 94\% of the isolates, $74 \%$ of these additionally showed R58. Mutations at codons 57 and 61 were found in only one specimen each (Table 2). 
Table I: Prevalence of mutations conferring resistance to chloroquine and sulfadoxine-pyrimthamine in Plasmodium falciparum isolates from southern Ethiopia $(n=69)$

\begin{tabular}{lll}
\hline Gene locus & Mutation (\%) & Mixed type (\%) \\
\hline Pfcrt 76 & $69(100 \%)$ & $0(\%)$ \\
Pfmdrl 86 & $45(65 \%)$ & $11(16 \%)$ \\
Dhfr 5I & $67(97 \%)$ & $0(\%)$ \\
Dhfr 108 & $69(100 \%)$ & $0(\%)$ \\
Dhfr 59 & $62(90 \%)$ & $0(\%)$ \\
Dhps 436 & $0(0 \%)$ & $0(\%)$ \\
Dhps 437 & $67(97 \%)$ & $0(\%)$ \\
Dhps 540 & $67(97 \%)$ & $0(\%)$ \\
Dhps 58I & $0(0 \%)$ & $0(\%)$ \\
Dhps 6I3 & $0(0 \%)$ & $0(\%)$ \\
& & \\
Grouped dhfr/dhps alleles & & $0(\%)$ \\
Dhfr 15I+NI08 & $7(10 \%)$ & $0(\%)$ \\
Dhfr R59+NI08 & $2(3 \%)$ & $0(\%)$ \\
Dhfr triple (I5I+R59+NI08) & $60(87 \%)$ & $0(\%)$ \\
Dhfr/dhps quadruple (dhfr triple + dhps G437) & $0(0 \%)$ & $0(\%)$ \\
Dhfr/dhps quintuple (quadruple + dhps E540) & $59(86 \%)$ & \\
\hline
\end{tabular}

a both wildtype and mutant allele were found

\section{Discussion}

Ethiopia comprises regions of largely differing malaria endemicity and transmission. Considering the substantial burden of disease in this country, there is a remarkable shortage on country-wide data on the efficacy of antimalarial drugs. A failure rate of $88 \%$ within two weeks following CQ treatment was reported from central Ethiopia already in 1999 [21]. A recent multi-site survey demonstrated mean SP treatment failure rates of $36 \%$ and $72 \%$ within two and four weeks of follow-up, respectively [22]. $\mathrm{AL}$, in contrast, was reported to achieve adequate clinical and parasitological response in 99\% [22].

In line with reports on high clinical failure rates of CQ and SP, the obtained data shows that in an area of seasonal transmission in southern Ethiopia, P. falciparum mutations conferring resistance to these drugs are abundant. In particular, pfcrt T76 and the pfdhfr triple mutation occurred in $100 \%$ and almost $90 \%$, respectively. Also, $p f d$ hfr G437 and E540 considered to confer high grade SP resistance in the presence of the $p f d h f r$ triple mutant [10] were seen in all but two $P$. falciparum isolates. In addition, with the exception of $p f m d r 1$, mixed alleles comprising both wildtype and mutation, were absent. Although only approximative evidence, this suggests a rather low multiplicity of infection according with the seasonal nature of malaria transmission in the study area.

The prevalence of $p f d h f r$ triple and $p f d h f r / p f d h p s$ quintuple $(86 \%)$ mutations found in this study is extraordinarily high. In Malawi, roughly three out of four patients infected with parasites exhibiting quintuple mutations have been reported to suffer SP treatment failure [10]. So far, the predictive value of these markers for SP treatment failure has neither been established in Ethiopia nor in the study area. Though this predictive value may show some variation between different locations [10,11], however, overall and considering respective studies in East Africa $[23,10]$ these findings match with the extremely poor SP efficacy rates seen in this country [4]. In Jima, southern Ethiopia and some $200 \mathrm{~km}$ West of Dilla, 54\% of P. falciparum isolates have recently been reported to carry the $p f d$ $h f r / p f d h p s$ quintuple mutation [24] highlighting the uneven distribution of drug resistance in the country. Furthermore, the prevalence of quintuple mutants in the present study exceeds respective numbers in other African

Table 2: Prevalence of Plasmodium vivax dihydrofolate reductase mutations associated with resistance to sulfadoxine-pyrimthamine in isolates from southern Ethiopia $(n=31)$

\begin{tabular}{llll}
\hline Pvdhfr codon & Wildtype (\%) & Mutation (\%) & Mixed (\%) \\
\hline 57 & $30(97 \%)$ & $1(3 \%)$ & 0 \\
58 & $8(26 \%)$ & $21(68 \%)$ & $2(6 \%)$ \\
61 & $30(97 \%)$ & 0 & $1(3 \%)$ \\
117 & $2(6 \%)$ & $29(94 \%)$ & 0 \\
\hline
\end{tabular}

a both wildtype and mutant allele were found 
countries where SP had been used for a longer period of time $[23,25]$. The reason for the abundance of mutations conferring SP resistance in the study area of Dilla remains obscure but the findings definitely supports usage of an alternative first-line drug, e.g. AL.

$P f c r t$ T76, and to a lesser extent $p f m d r 1$ Y86, are useful markers of CQ resistance in areas where it is low to moderate $[20,26]$. In the present study, the high prevalence of $p f c r t$ and $p f m d r 1$ mutations match the known poor efficacy of CQ in Ethiopia [21]. However, considering the retraction of the drug at least from official first-line treatment, perpetuation of resistant strains in the parasite population due to ongoing CQ usage also seems possible. Unfortunately, pre-treatment drug levels could not be assessed in the present study. Nevertheless, the obtained results on CQ resistance markers may have importance for subsequent monitoring: In areas where CQ was abandoned as first-line antimalarial, a recovery of CQ sensitivity and a decrease of pfcrt mutations have been demonstrated $[27,28]$.

For $P$. vivax, high frequencies of pvdhfr N117 (94\%) and N117-R58 (74\%) variations but no T117, triple or quadruple mutations were observed. Although these multiple mutations seem to be necessary for in vivo resistance $[13,14]$, this finding suggests widespread SP use since the former arise first under drug pressure $[13,14]$. Higher frequencies of pvdhr mutations are only found in Thailand where double and triple mutations were detected in $99 \%$ of isolates [13]. P. vivax substantially contributes to morbidity in Ethiopia and differentiating $P$. falciparum from $P$. vivax frequently is hampered by limited or absent microscopic facilities. As this implies SP treatment of $P$. vivax malaria, monitoring the resistance patterns seems worthwhile.

\section{Conclusion}

In conclusion, $P$. falciparum mutations conferring resistance to CQ and SP are abundant in southern Ethiopia as are mutations in $P$. vivax associated with SP resistance. These findings strongly support the withdrawal of CQ and SP and the introduction of AL as first-line drug for the treatment of falciparum malaria. Repeated surveillance of the parasites' molecular markers will enable to monitor the development of resistance to CQ and SP in the region.

\section{Authors' contributions}

FPM, WPW, TL and UB designed the study. WPW, TL, and UB were responsible for patient recruitment and parasitological examinations. MS, IBM, MEO, and SR did the PCR assays. MS and FPM wrote the paper with major contributions of the other authors.

\section{Conflict of interest}

The author(s) declare that they have no competing interests.

\section{Financial support}

Charité grant 89539150 (2005).

\section{References}

I. Abeku TA, van Oortmarssen G], Borsboom G, de Vlas SJ, Habbema $\mathrm{J}$ : Spatial and temporal variations of malaria epidemic risk in Ethiopia: factors involved and implications. Acta Trop 2003, 87:331-340.

2. RBM Baseline survey in selected districts in Ethiopia. Report $200 \mathrm{I}$. Ministry of Health, Addis Ababa, Ethiopia.

3. Das P: Ethiopia faces severe malaria epidemic. Lancet 2003, 362:2071.

4. Jima D, Tesfaye G, Medhin A, Kebede A, Argaw D, Babaniyi O: Efficacy of sulfadoxine-pyrimethamine for the treatment of uncomplicated falciparum malaria in Ethiopia. East Afr Med J 2005, 82:391-395.

5. Assessment of the therapeutic efficacy of antimalarial drugs in Ethiopia. Ministry of Health, Addis Ababa, Ethiopia.

6. Derressa W, Ali A, Enqusellassie F: Self-treatment of malaria in rural communities, Butajira, southern Ethiopia. Bull World Health Organ 2003, 81:261-268.

7. Fidock DA, Nomura T, Talley AK, Cooper RA, Dzekunov SM, Ferdig MT, Ursos LM, Sidhu AB, Naude B, Deitsch KW, Su XZ, Wootton JC, Roepe PD, Wellems TE: Mutations in the $P$. falciparum digestive vacuole transmembrane protein PfCRT and evidence for their role in chloroquin resistance. Mol Cell 2000, 6:861-87I.

8. Sanchez C, Lanzer M: Changing ideas on chloroquine in Plasmodium falciparum. Curr Opin Infect Dis 2000, 13:653-658.

9. Wernsdorfer WH, Noedl H: Molecular markers for drug resistance in malaria: use in treatment, diagnosis and epidemiology. Curr Opin Infect Dis 2003, 16:553-558.

10. Kublin JG, Dzinjalamala FK, Kamwendo DD, Malkin EM, Cortese JF, Martino LM, Mukadam RA, Rogerson SJ, Lescano AG, Molyneux ME, Winstanley PA, Chimpeni P, Taylor TE, Plowe CV: Molecular markers for failure of sulfadoxine-pyrimethamine and chlorproguanil-dapsone treatment of Plasmodium falciparum malaria. $j$ Infect Dis 2002, 185:380-388.

II. Mockenhaupt FP, Bousema TJ, Eggelte TA, Schreiber J, Ehrhardt S, Wassilew N, Otchwemah RN, Sauerwein RW, Bienzle U: Plasmodium falciparum dhfr but not dhps mutations associated with sulphadoxine-pyrimethamine treatment failure and gametocyte carriage in northern Ghana. Trop Med Int Health 2005, 10:901-908

12. Young MD, Burgess RW: Pyrimethamine resistance in Plasmodium vivax malaria. Bull World Health Organ 1959, 20:27-36.

13. Imwong M, Pukrittakayamee S, Looareesuwan S, Pasvol G, Poirreiz J, White NJ, Snounou G: Association of genetic mutations in $P$. vivax dhfr with resistance to sulfadoxine-pyrimethamine: geographical and clinical correlates. Antimicrob Agents Chemother 200I, 45:3I22-3I27.

14. Imwong M, Pukrittakayamee S, Rénia L, Letourneur F, Charlieu JP, Leartsakulpanich U, Looareesuwan S, White NJ, Snounou G: Novel point mutations in the dihydrofolate reductase gene of Plasmodium vivax: evidence for sequential selection by drug pressure. Antimicrob Agents Chemother 2003, 47:1514-1521.

15. Kippie T: Five Thousand Years of Sustainability? A case study on Gedeo land use. Treemail Publisher, Heelsum, Netherlands; 2002.

16. Malaria Diagnosis and Treatment Guidelines for Health Workers in Ethiopia. Ministry of Health, Addis Ababa, Ethiopia.

17. Snounou G, Viriyakosol S, Zhu XP, Jarra W, Pinheiro L, do Rosario VE, Thaithong S, Brown KN: High sensitivity of detection of human parasites by the use of nested polymerase chain reaction. Mol Biochem Parasitol 1993, 61:315-320.

18. Duraisingh MT, Curtis J, Warhurst DC: Plasmodium falciparum: detection of polymorphisms in the dihydrofolate reductase and dihydropteroate synthetase genes by PCR and restriction digestion. Exp Parasitol 1998, 89: I-8. 
19. Flueck TP, Jelinek T, Kilian AH, Adagu IS, Kabagambe G, Sonnenburg $\mathrm{F}$, Warhurst DC: Correlation of the in vivo-resistance to chloroquine and allelic polymorphisms in Plasmodium falciparum isolates from Uganda. Trop Med Int Health 2000, 5: 174-I78.

20. Djimde A, Doumbo O, Cortese JF, Kayentao K, Doumbo S, Diourte Y, Dicko A, Su XZ, Nomura T, Fidock DA, Wellems TE, Plowe CV, Coulibaly D: A molecular marker for chloroquin-resistant falciparum malaria. N Engl J Med 200I, 344:257-263.

21. Kebede F, Taffa N, Tedla T: An in-vivo study of falciparum malaria sensitivity to chloroquine in unstable malaria endemic area of central Ethiopia. Ethiop Med J 1999, 37:97-109.

22. Jima D, Tesfaye G, Medhin A, Kebede A, Argaw D, Babaniyi O: Safety and efficacy of artemether-lumefantrine in the treatment of uncomplicated falciparum malaria in Ethiopia. East Afr Med J 2005, 82:397-390.

23. Nzila AM, Mberu EK, Sulo J, Dayo H, Winstanley PA, Sibley CH, Watkins WM: Towards an understanding of the mechanism of pyrimethamine-sulfadoxine resistance in Plasmodium falciparum: genotyping of dihydrofolate reductase and dihydropteroate synthetase of Kenyan parasites. Antimicrob Agents Chemother 2000, 44:991-996.

24. Gebru-Woldearegai T, Hailu A, Grobusch MP, Kun JF: Molecular surveillance of mutations in DHFR and DHPS genes of Plasmodium falciparum in Ethiopia. Am J Trop Med Hyg 2005, 73:II3I-II34.

25. Bwijo B, Kaneko A, Takechi M, Zungu LL, Moriyama Y, Lum JK, Tsukahara T, Mita T, Takahashi N, Bergqvist Y, Bjorkman A, Kobayakawa $\mathrm{T}$ : High prevalence of quintuple mutant dhps/dhfr genes in Plasmodium falciparum infections seven years after introduction of sulfadoxine and pyrimethamine as first line treatment in Malawi. Acta Trop 2003, 85:363-373.

26. Mockenhaupt FP, Ehrhardt S, Eggelte TA, Agana-Nsiire P, Stollberg K, Mathieu A, Markert M, Otchwemah RN, Bienzle U: Chloroquinetreatment failure in northern Ghana: roles of pfcrt T76 and pfmdrl Y86. Ann Trop Med Parasitol 2005, 99:723-732.

27. Kublin JG, Cortese JF, Njunju EM, Mukadam RA, Wirima JJ, Kazembe PN, Djimde AA, Kouriba B, Taylor TE, Plowe CV: Re-emergence of chloroquine sensitive Plasmodium falciparum Malaria after the cessation of chloroquine use in Malawi. J Infect Dis 2003, I 87: 1870-1875.

28. Mita T, Kaneko A, Lum JK, Bwijo B, Takechi M, Zungu IL, Tsukahara $\mathrm{T}$, Tanabe K, Kobayakawa T, Bjorkman A: Recovery of chloroquine sensitivity and low prevalence of the Plasmodium falciparum chloroquine resistance transporter gene mutation K76T following the discontinuance of chloroquine use in Malawi. Am J Trop Med Hyg 2003, 68:413-4I5.

\section{Publish with Bio Med Central and every scientist can read your work free of charge}

"BioMed Central will be the most significant development for disseminating the results of biomedical research in our lifetime. "

Sir Paul Nurse, Cancer Research UK

Your research papers will be:

- available free of charge to the entire biomedical community

- peer reviewed and published immediately upon acceptance

- cited in PubMed and archived on PubMed Central

- yours - you keep the copyright

Submit your manuscript here:

http://www.biomedcentral.com/info/publishing_adv.asp
BioMedcentral 